\title{
Headspace Solid-Phase Microextraction Gas Chromatography-Mass Spectrometry and Gas Chromatography-Olfactometry Analysis of Volatile Compounds in Pineapple Breads
}

\author{
Saw Ying ${ }^{1}$, Ola Lasekan ${ }^{1, *}$, Kalla Reddi Mohan Naidu ${ }^{1}$ and Seye Lasekan ${ }^{2}$ \\ 1 Department of Food Technology, Faculty of Food Science and Technology, \\ University Putra Malaysia, UPM, 43400, Serdang, Malaysia \\ 2 Department of Food Science, Faculty of Food Science and Technology, University Putra Malaysia, \\ UPM, 43400, Serdang, Malaysia
}

* Author to whom correspondence should be addressed; E-Mail: lasekan@food.upm.edu.my; Tel.: +603-8946-8535; Fax: +603-8942-3552.

Received: 9 July 2012; in revised form: 5 November 2012 / Accepted: 13 November 2012 / Published: 22 November 2012

\begin{abstract}
Sensorial analysis of pineapple breads (conventionally baked, Cpb; fully baked frozen, Fpb and partially baked, Ppb) showed no significant differences in terms of aroma and taste. On the contrary, the scores for the overall quality between the partially baked and conventionally baked breads showed significant $(p<0.05)$ differences. At the same time, headspace analysis using a solid-phase microextraction (SPME) method identified 59 volatile compounds. The results of the aroma extracts dilution analysis (AEDA) revealed 19 most odour-active compounds with FD factors in the range of 32-128 as the key odourants of the pineapple breads. Further analysis of the similarities and differences between the pineapple breads in terms of the key odourants were carried out by the application of PLS-DA and PLS-regression coefficients. Results showed that Ppb exhibited strong positive correlations with most of the volatile- and non-volatile compounds, while the Cpb showed significant positive correlations with hexanal and 4-hydroxy-2,5-dimethyl$3(2 H)$-furanone, and the Fpb had strong positive correlations with lactic acid, benzoic acid, benzaldehyde and ethyl propanoate.
\end{abstract}

Keywords: pineapple bread; conventionally baked; fully frozen baked; partially baked; volatiles 


\section{Introduction}

Bread quality is normally defined by its volume, texture, colour and flavour. However, the characteristic aroma of bread is undoubtedly one of the most important parameters influencing its acceptance by consumers [1]. Bread aroma has been widely studied and many methods to identify the compounds responsible for its flavour have been developed [2]. The flavour of bread is a result of the interaction of many factors, and depends on a large number of compounds, the majority of them with different olfactive characteristics. More than 540 compounds have been described in the complex aromatic fraction of bread [3]. All these compounds do not have same degree of influence on bread flavour [4]. Quantitatively, the most important groups are the alcohols, aldehydes, esters, ketones, acids, pyrazines and the pyrrolines [2,5].

On the one hand, the type of flour and other ingredients could influence the flavour [6], and on the other, the type of fermentation can also significantly influence bread flavour. Finally, the production process also has a vital influence on the flavour [7]. Flavour chemists are now showing more interest in volatile compounds which contribute significantly to the overall aroma of bread. Different extraction methods and analytical techniques have been employed with the aim of identifying these volatile compounds.

Several extraction techniques have been used, ranging from solvent extraction [8], distillation [3] to vacuum distillation [9]. Bread flavour components were then characterized by coupling headspace measurements with olfactometric methods such as aroma extracts dilution analysis (AEDA) [10], Solid-phase microextraction (SPME) is currently widely employed in food analysis. SPME has become one of the preferred techniques in aroma analysis, offering solvent free, rapid sampling with low cost and easy preparation. It is sensitive, selective and compatible with low detection limits [11-13].

In recent times, many types of breads supplemented with various nutritious, protective and filler substances have been gaining popularity worldwide [14]. The desire of consumers for healthier and fresher foods calls for a concerted effort on the part of food scientists to address such needs. Pineapple breads produced by replacing completely table sugar with concentrated pineapple juice [15] have become very popular among local communities. Pineapple juice contains high contents of trace elements (K, P, Ca, Na, Fe and vitamins $\mathrm{C}$ and A) [16]. Due to an increasing consumer demand for fresh bread, new technologies have been developed to offer consumers fresh bread at all times. Among these is the application of the "green dough" technology [11], in which the dough is first frozen before proofing. A first partial baking stage can also be added to the process, followed by refrigeration and storage at room temperature, or by storage under freezing conditions. These technologies produce partially baked bread and partially baked frozen bread, respectively [11]. These different breads are important in terms of innovation and they offer fresh bread after a simple final baking stage at retail outlets. The present research aims to study the composition of volatile- and non-volatile constituents in pineapple breads (i.e., conventionally baked, fully baked frozen and partially baked) using HS-SMPE coupled with GC-MS/GC-O. 


\section{Results and Discussion}

\subsection{Calibration, Linearity and Recovery}

The quality parameters (linearity range, LOD and recovery \%) of the major volatile compounds quantified from the pineapple breads are shown in Table 1 . The recoveries were good $(>87.8 \%)$. This was followed by an excellent linearity in all cases. The limits of detection (LOD) which is the lowest concentration at which the results still satisfy some predetermined acceptance criteria or the mean blank value plus $(3 \times$ the relative standard deviation of the analytical blank values) [17] were low enough to determine the aroma compounds in the pineapple breads.

Table 1. Major volatile compounds and their performance characteristics quantified from pineapple bread.

\begin{tabular}{lccc}
\hline \multicolumn{1}{c}{ Compounds No. } & $\begin{array}{c}\text { Linear range } \\
\left(\boldsymbol{\mu g . \mathbf { g } ^ { - 1 } )}\right.\end{array}$ & $\begin{array}{c}\text { Limit of detection } \\
\left(\mathbf{L O D}, \boldsymbol{\mu g . g ^ { - 1 } )}\right.\end{array}$ & $\begin{array}{c}\text { Recovery } \\
(\mathbf{\%})\end{array}$ \\
\hline 1. Acetic acid & $10-200$ & 5.92 & 97.4 \\
2. Propanoic acid & $5-250$ & 1.27 & 98.1 \\
3. Hexanoic acid & $20-250$ & 9.81 & 90.4 \\
4. Benzoic acid & $10-250$ & 8.65 & 89.4 \\
5. Ethanol & $10-200$ & 5.82 & 87.8 \\
6. 2/3-Methyl-1-butanol & $10-150$ & 7.14 & 98.5 \\
7. 2-Phenylethanol & $10-200$ & 4.53 & 94.8 \\
8. Hexanal & $10-200$ & 7.34 & 90.1 \\
9. Benzaldehyde & $10-250$ & 6.33 & 95.3 \\
10. (E,E)-2,4-decadienal & $10-150$ & 5.98 & 91.4 \\
11. 2,3-Butanedione & $10-250$ & 6.72 & 97.4 \\
12. 3-Hydroxy-2-butanone & $10-250$ & 6.32 & 96.2 \\
13. Ethyl acetate & $10-200$ & 7.4 & 99.1 \\
14. Ethyl propanoate & $10-200$ & 9.13 & 92.7 \\
15. Methyl ethanoate & $10-250$ & 4.37 & 96.3 \\
16. Ethyl octanoate & $10-200$ & 7.09 & 90.4 \\
17. Furfural & $10-200$ & 5.97 & 90.6 \\
18. Furfury alcohol & $10-250$ & 6.54 & 94.4 \\
19. 2-Methylpropanoic acid & $10-200$ & 8.35 & 90.8 \\
20. 2,3-Dihydroxy-6-methyl-4H-pyran-4 one & $10-250$ & 7.66 & 91.3 \\
21. 4-Hydroxy-2,5-dimethyl-3(2H)-furanone & $10-200$ & 5.78 & 96.7 \\
\hline
\end{tabular}

\subsection{Sensory Evaluation of Breads}

The sensory evaluation showed appreciable differences among the different pineapple bread types (Table 2). The best results were obtained in the case of the partially baked pineapple bread (Ppb), while the conventionally baked pineapple bread $(\mathrm{Cpb})$ recorded the lowest scores. Statistical analysis (one-way ANOVA) showed that the scores for aroma and taste between all types of pineapple breads were not significantly different $(p>0.05)$. On the contrary, the scores for the overall quality between partially baked pineapple bread and conventionally baked bread showed significant $(p<0.05)$ 
differences. The overall quality is that sensational attributes that makes a product fundamentally different from others. Some of the factors contributing towards quality of food are; appearance, colour, taste, aroma, adulterants and nutritional value. While the Ppb produced higher intensity of dough and sourdough flavour with slight fruity notes, the $\mathrm{Cpb}$ and $\mathrm{Fpb}$ had lower flavour nuances.

Table 2. Panellists' sensory evaluation of pineapple bread samples (CPB, FPB and PPB).

\begin{tabular}{|c|c|c|c|}
\hline \multirow{2}{*}{ Attributes } & \multicolumn{3}{|c|}{ Bread type * } \\
\hline & $\mathrm{CPb}$ & $\mathbf{F P b}$ & $\mathbf{P P b}$ \\
\hline Aroma & $7.1 \pm 0.1^{\mathrm{ab}}$ & $7.6 \pm 0.1^{\mathrm{a}}$ & $8.0 \pm 0.2^{\mathrm{a}}$ \\
\hline Taste & $7.4 \pm 0.2^{\mathrm{a}}$ & $8.0 \pm 0.1^{\mathrm{a}}$ & $8.4 \pm 0.1^{\mathrm{a}}$ \\
\hline Overall quality & $7.0 \pm 0.1^{\mathrm{b}}$ & $8.3 \pm 0.1^{\mathrm{a}}$ & $8.7 \pm 0.1^{\mathrm{a}}$ \\
\hline
\end{tabular}

* Mean \pm SD with the same superscripts are not significantly $(p>0.05)$ different; $\mathrm{CPb}$ : Conventional pineapple bread, FPb: Fully frozen pineapple bread, PPb: Partially baked pineapple bread.

\subsection{Identification of Volatile Compounds}

To elucidate the molecular principles responsible for the observed aroma impressions, the flavour volatile compounds of the pineapple breads were first isolated by means of headspace solid-phase microextraction and were subsequently analysed by means of gas chromatography-olfactometry, as well as mass spectrometry. This method and the application of the aroma extract dilution analysis (AEDA) led to the detection of 59 odour-active compounds in the FD factor range of 2-128. These compounds, together with their odour impressions and retention indices are shown in Table 3.

The complex chemical and enzymatic reactions which occurred during fermentation and baking gave rise to a number of volatile and non-volatile compounds. It is likely that these compounds in no doubt contributed to the overall flavour of the final pineapple bread. In this study, the identified volatile compounds comprised eight acids, eight alcohols, 12 aldehydes, 12 ketones, 10 esters and three furan derivatives (Table 3). In general, all main classes of compounds commonly listed as thermally generated flavours in baked breads were identified in the pineapple breads ( $\mathrm{Cpb}, \mathrm{Fpb}$ and $\mathrm{Ppb}$ ). The flavour compounds revealed fruity (nos. 1, 5, 8, 15, 17, 26, 46, 56, and 58), buttery (nos. 4, 7 and 45), roasty (nos. 29, 35 and 37), sweaty (nos. 14, 23, 28 and 50), fatty (nos. 27, 33, 42, 43, 44, 48 and 54) odour qualities. Also, diverse sweet, malty, vanilla- or honey-like/flowery compounds were detected (nos. 9, 18, 25, 30, 36, 38, 49, 57 and 59) (Table 3). It is noteworthy that aroma compound number 20 (Table 3) with popcorn-like aroma failed to yield any signal at the flame ionization detector. This indicated a very low odour threshold for this compound. This compound was later characterized by co-injection with the reference compound on the DB-5 column (Table 3) and its odour quality at the sniffing port revealed it to be 2-acetyl-1-pyrroline. 
Table 3. Volatile compounds identified in pineapple breads (conventionally processed, $\mathrm{CPb}$; fully frozen, Fpb and partially baked, Ppb).

\begin{tabular}{|c|c|c|c|c|c|}
\hline Number & Odourant $^{a}$ & Odour quality ${ }^{b}$ & FD & Retention index DB-5 & $\begin{array}{c}\text { Previously identified } \\
\text { in bread }^{\mathrm{c}}\end{array}$ \\
\hline 1 & Ethyl acetate & Pineapple-like & 32 & 628 & 2,4 \\
\hline 2 & Propanoic acid & Rancid & 32 & 668 & 4,7 \\
\hline 3 & Methyl-2-methylpropionate & Fruity, sweet & 4 & 687 & 9 \\
\hline 4 & 2,3-Pentanedione & Buttery & 16 & 710 & $1,4,5 \& 10$ \\
\hline 5 & Ethyl propionate & Fruity & 64 & 713 & \\
\hline 6 & Butanoic acid & sour & 2 & 718 & 4,5 \\
\hline 7 & 3-Hydroxy-2-butanone & Buttery & 64 & 720 & 2,3 \\
\hline 8 & Ethyl-2-methyl propionate & Sweet-fruity & 4 & 754 & $4,6,9$ \\
\hline 9 & 2-/3Methyl-1-butanol & Malty & 128 & 769 & $2,3,4$ \\
\hline 10 & 1-Hexen-3-one & Green & 2 & 774 & $1,4,10$ \\
\hline 11 & Hexanal & Green, tallow & 32 & 787 & $1,2,3,7$ \\
\hline 12 & 2,3-Butanediol & Fruity, onion & 8 & 802 & 1,2 \\
\hline 13 & Furfural & Bread-like & 64 & 826 & $1,2,3$ \\
\hline 14 & 2-Methyl butanoic acid & Sweaty & 16 & 831 & 1,4 \\
\hline 15 & Ethyl-2-methyl butanoate & Fruity & 8 & 838 & 9 \\
\hline 16 & Furfuryl alcohol & Burnt & 16 & 863 & \\
\hline 17 & Methyl ethanoate & Fruity & 32 & 864 & 4 \\
\hline 18 & (Z)-4-Heptenal & Biscuit-like, sweet & 16 & 894 & $1,4,5,6,7,10$ \\
\hline 19 & Methional & cooked-potato & 4 & 919 & $4,5,6,7,10$ \\
\hline 20 & 2-Acetyl-1-pyrroline ${ }^{\mathrm{d}}$ & Popcorn-like & 16 & 922 & $4,5,6,10$ \\
\hline 21 & Benzaldehyde & Almond-like & 64 & 936 & 4,7 \\
\hline 22 & Ethanol & Alcoholic & 32 & 945 & 3,6 \\
\hline
\end{tabular}


Table 3. Cont.

\begin{tabular}{|c|c|c|c|c|c|}
\hline Number & Odourant $^{a}$ & Odour quality ${ }^{b}$ & FD & Retention index DB-5 & $\begin{array}{c}\text { Previously identified } \\
\text { in bread }^{\mathrm{c}} \\
\end{array}$ \\
\hline 23 & Hexanoic acid & Sweaty & 32 & 961 & $1,3,4$ \\
\hline 24 & 1-Octen-3-one & Mushroom-like & 4 & 970 & $1,4,5,10$ \\
\hline 25 & (Z)-1,5-Octadien-3-one & Geranium-like & 2 & 987 & $4,5,7,9$ \\
\hline 26 & Ethyl hexanoate & Fruity (apple) & 8 & 1002 & $1,2,9$ \\
\hline 27 & Octanal & Soapy, fatty & 4 & 1006 & $1,4,9$ \\
\hline 28 & 4-Hydroxybutanoic acid & Sweaty & 16 & 1018 & \\
\hline 29 & Acetylpyrazine & Toasty & 4 & 1030 & $1,4,7,10$ \\
\hline 30 & Phenylacetaldehyde & Honey-like & 16 & 1042 & $2,4,5,7$ \\
\hline 31 & $\begin{array}{c}\text { Tetrahydro-6-methyl-2H-pyran-2- } \\
\text { one }\end{array}$ & Coconut & 2 & 1050 & 1,2 \\
\hline 32 & $\begin{array}{l}\text { 4-Methoxy-2,5-dimethyl-3 }(2 H) \text { - } \\
\text { furanone }\end{array}$ & Caramel-like & 16 & 1057 & 9 \\
\hline 33 & $(E)$-2-Octenal & Nutty, fatty & 8 & 1062 & $1,4,5,6,7$ \\
\hline 34 & $\begin{array}{l}\text { 4-Hydroxy-2,5-dimethyl-3(2H)- } \\
\text { furanone }\end{array}$ & Sweet, caramel & 32 & 1022 & $2,4,9$ \\
\hline 35 & 2-Ethyl-3,5-dimethylpyrazine & Roasty & 4 & 1080 & $4,5,7,10$ \\
\hline 36 & Linalool & Flowery & 4 & 1092 & 1,2 \\
\hline 37 & 2-acetyl-2-thiazoline & Roasty & 8 & 1108 & 4 \\
\hline 38 & 2-Phenylethanol & Honey & 128 & 1136 & $1,2,3,4,10$ \\
\hline 39 & 2-Propionyl-2-thiazole & Roasty & 2 & 1125 & 4,10 \\
\hline 40 & $\begin{array}{l}\text { 2,3-Dihydroxy-6-methyl-4H- } \\
\text { pyran-4-one }\end{array}$ & Caramel-sweet & 64 & 1141 & 8 \\
\hline 41 & 2,3-Diethyl-5-methylpyrazine & Earthy & 4 & 1157 & $4,7,10$ \\
\hline 42 & (E)-2-Nonenal & Fatty, green & 4 & 1164 & $4,5,6,7$ \\
\hline
\end{tabular}


Table 3. Cont.

\begin{tabular}{|c|c|c|c|c|c|}
\hline Number & Odourant $^{a}$ & Odour quality ${ }^{b}$ & FD & Retention index DB-5 & $\begin{array}{c}\text { Previously identified } \\
\text { in bread }^{c}\end{array}$ \\
\hline 43 & Ethyl octanoate & Fruity, fatty & 32 & 1201 & 1,5 \\
\hline 44 & $(E, E)$-2,4-Nonadienal & Fatty & 2 & 1220 & $1,4,5,6$ \\
\hline 45 & 2-Methylpropanoic acid & Buttery, rancid & 32 & 1221 & 4 \\
\hline 46 & Ethyl phenyl acetate & Fruity, sweet & 8 & 1253 & 1 \\
\hline 47 & $Y$-Octalactone & Coconut-like & 16 & 1261 & 1,9 \\
\hline 48 & Decanol & Fatty & 4 & 1269 & 1 \\
\hline 49 & 2-Phenylacetic acid & Honey & 8 & 1270 & 4 \\
\hline 50 & Benzoic acid & Sweaty & 32 & 1287 & \\
\hline 51 & $\delta$-Octalactone & Coconut-like & 2 & 1288 & $1,2,9$ \\
\hline 52 & Butyrolactone & Caramel, sweet & 4 & 1299 & 2 \\
\hline 53 & 4-Vinylguaiacol & Curry, clove & 4 & 1310 & 1,10 \\
\hline 54 & $(E, E)$-2,4-Decadienal & Fatty & 32 & 1313 & $1,4,5,6$ \\
\hline 55 & $\alpha$-Copaene & Wood & 2 & 1393 & 1 \\
\hline 56 & $\beta$-Damascenone & Sweet, fruity & 8 & 1393 & $1,4,7,9$ \\
\hline 57 & Vanillin & Vanilla-like & 16 & 1410 & $1,4,9$ \\
\hline 58 & $Y$-Decalactone & Fruity, peach-like & 4 & 1473 & 9 \\
\hline 59 & Ethyl octadecanoate & Flowery & 4 & 2205 & 1 \\
\hline
\end{tabular}

${ }^{a}$ The compounds were identified by comparing them with reference substances on the basis of the following criteria: retention index on DB-5 as given in the table, mass spectra obtained by MS (EI), and odour quality as well as odour intensity perceived at the sniffing port. ${ }^{b}$ Odour quality perceived at the sniffing port. ${ }^{\mathrm{c}}$ Reported in the literature as volatile compounds of bread in: ${ }^{1}$ Adams [18]; ${ }^{2}$ Elss et al. [19]; ${ }^{3}$ Jensen et al. [20]; ${ }^{4}$ Pozo-Bayon et al. [1]; ${ }^{5}$ Rychlik \& Grosch [8]; ${ }^{6}$ Schieberle \& Grosch [5]; ${ }^{7}$ Schieberle \& Grosch [21]; ${ }^{8}$ Silva et al. [22]; ${ }^{9}$ Tokitomo et al. [23]; ${ }^{10}$ Zehentbauer \& Grosch [24]. ${ }^{\mathrm{d}}$ The MS signal was too weak. The compound was later characterized by co-injection with reference compounds. 
The production of volatile compounds is generally influenced by dough fermentation [24], proofing and baking [25]. For instance, prolonged dough fermentation has been reported to increase the concentration of some volatile compounds such as 3-methylbutanol, 2-phenylethanol and ethanol [26]. These compounds are directly linked to the fermentative activity of the yeast in the dough fermentation step [27]. In the present study, compounds with appreciably high concentrations were ethanol, ethyl acetate, 2,3-butanedione, 3-hydroxy-2-butanone and ethyl propionate (Table 4). Interestingly, the partially baked pineapple bread (Ppb) recorded the highest concentration of odourants in all cases (Table 4). This is probably due to the slightly higher fermentation time of the Ppb, which might have produced appreciable amounts of free amino acids. The free amino acids can act as precursors of the Strecker reaction leading to the increases obtained in odourant's concentration [26].

Table 4. Most odour-active volatile compounds $(F D>32)$ identified in pineapple bread samples (Cpb, Fpb and $\mathrm{Ppb}$ ) *.

\begin{tabular}{|c|c|c|c|}
\hline Compound & $\mathrm{CPb}$ & Fpb & Ppb \\
\hline \multicolumn{4}{|l|}{ ACIDS } \\
\hline Propanoic acid & $0.03 \pm 0.0$ & $0.02 \pm 0.0$ & $0.35 \pm 0.0$ \\
\hline 2-Methylpropanoic acid & $0.07 \pm 0.0$ & $0.07 \pm 0.0$ & $0.14 \pm 0.0$ \\
\hline Hexanoic acid & $0.03 \pm 0.0$ & $0.03 \pm 0.0$ & $0.11 \pm 0.0$ \\
\hline Benzoic acid & $0.30 \pm 0.01$ & $0.33 \pm 0.01$ & $0.45 \pm 0.01$ \\
\hline \multicolumn{4}{|l|}{ ALCOHOLS } \\
\hline Ethanol & $2.16 \pm 0.01$ & $2.14 \pm 0.02$ & $2.35 \pm 0.01$ \\
\hline 2/3-Methyl-1-butanol & $0.15 \pm 0.0$ & $0.16 \pm 0.0$ & $1.67 \pm 0.01$ \\
\hline 2-Phenylethanol & $0.18 \pm 0.0$ & $0.18 \pm 0.0$ & $0.89 \pm 0.01$ \\
\hline \multicolumn{4}{|l|}{ ALDEHYDES } \\
\hline Hexanal & $0.53 \pm 0.0$ & $0.51 \pm 0.01$ & $0.50 \pm 0.02$ \\
\hline Benzaldehyde & $0.71 \pm 0.01$ & $0.73 \pm 0.02$ & $0.68 \pm 0.01$ \\
\hline$(E, E)$-2,4-Decadienal & $1.03 \pm 0.2$ & $1.03 \pm 0.07$ & $1.14 \pm 0.02$ \\
\hline \multicolumn{4}{|l|}{ KETONES } \\
\hline 2,3-Butanedione & $1.76 \pm 0.06$ & $1.75 \pm 0.03$ & $2.04 \pm 0.12$ \\
\hline 3-Hydroxy-2-butanone & $1.77 \pm 0.03$ & $1.79 \pm 0.01$ & $1.87 \pm 0.11$ \\
\hline 2,3-Dihydroxy-6-methyl-4H-Pyran-4-one & $0.04 \pm 0.0$ & $0.05 \pm 0.0$ & $1.35 \pm 0.1$ \\
\hline \multicolumn{4}{|l|}{ ESTERS } \\
\hline Ethyl acetate & $4.28 \pm 0.3$ & $4.29 \pm 0.5$ & $5.28 \pm 0.2$ \\
\hline Ethyl propionate & $1.63 \pm 0.02$ & $1.60 \pm 0.02$ & $1.57 \pm 0.01$ \\
\hline Methyl ethanoate & $0.06 \pm 0.0$ & $0.06 \pm 0.0$ & $0.05 \pm 0.0$ \\
\hline Ethyl octanoate & $1.05 \pm 0.06$ & $1.05 \pm 0.0$ & $1.06 \pm 0.0$ \\
\hline \multicolumn{4}{|l|}{ FURANS } \\
\hline 4-Hydroxy-2,5-dimethyl-3(2H)-furanone & $1.33 \pm 0.6$ & $1.37 \pm 0.1$ & $1.35 \pm 0.1$ \\
\hline Furfural & $0.93 \pm 0.01$ & $1.01 \pm 0.0$ & $1.95 \pm 0.1$ \\
\hline \multicolumn{4}{|l|}{ NON-VOLATILES } \\
\hline Lactic acid $(\mu \mathrm{g} / \mathrm{g})$ & $37.1 \pm 2.5$ & $38.7 \pm 1.0$ & $54.2 \pm 5.7$ \\
\hline TTA $^{1}$ & $1.42 \pm 0.1$ & $1.44 \pm 0.2$ & $2.03 \pm 0.1$ \\
\hline
\end{tabular}

$* \mu \mathrm{g}$ equivalents of 1-butanol per gram of bread. ${ }^{1} \mathrm{~mL} \mathrm{NaOH} 0.1 \mathrm{~N} / 10 \mathrm{~g}$ of bread. 


\subsection{Multivariate Analysis}

In order to examine the similarities and differences between the three pineapple breads $(\mathrm{Cpb}, \mathrm{Fpb}$ and $\mathrm{Ppb}$ ) in terms of the volatile compounds associated with each sample, principal component analysis (PCA) was employed. PCA provided easy visualisation of the complete data set in a reduced dimension plot, showing variability between volatile- and non-volatile compounds of breads. This method was employed to establish relationships between pineapple breads ( $\mathrm{Cpb}, \mathrm{Fpb}$ and $\mathrm{Ppb}$ ) and their flavour volatile compounds (Table 4). Based on the bread samples' grouping from PCA, a partial least square discriminant analysis (PLS-DA) was established (Figure 1). The scatter plot of scores of the first two components (in the PLS-DA which explained $92.53 \%$ of the total variance in the data) showed the distinctions among the different pineapple breads.

Figure 1. Score scatter plot of PLS-DA to show the similarities and differences between the pineapple breads. A: Conventionally baked $(\mathrm{Cpb})$; B: Fully frozen baked $(\mathrm{Fpb})$ and $\mathrm{C}$ : Partially baked (Ppb).
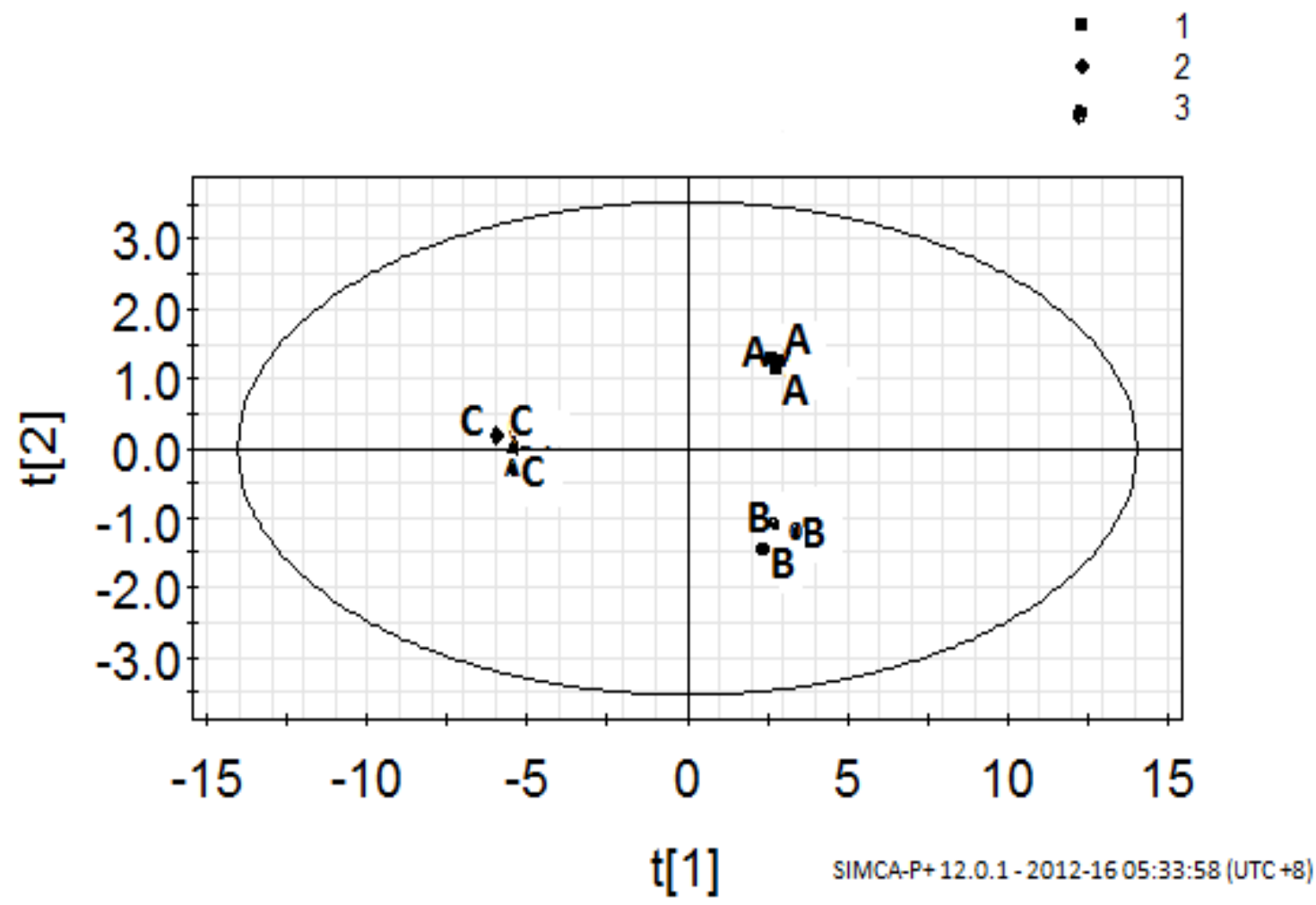

The PLS-DA model (which was based on three replicates and three breads) was however, validated using the response of permutation test through 100 permutations (Figure 2). A model is said to be valid when the intercept of R2 is $<0.3$ and intercept of Q2 is $<0.05$ [25]. In this study, the R2 is 0.271 and Q2 is -0.182 respectively. This plot (Figure 2) strongly indicates that the original model is valid because the regression line of the Q2-point intersects the vertical axis on the left and below zero. 
Figure 2. The validation plot for PLS and PLS-DA models. Intercepts: R2 $=(0.0,0.271)$, $\mathrm{Q} 2=(0.0,-0.182)$.

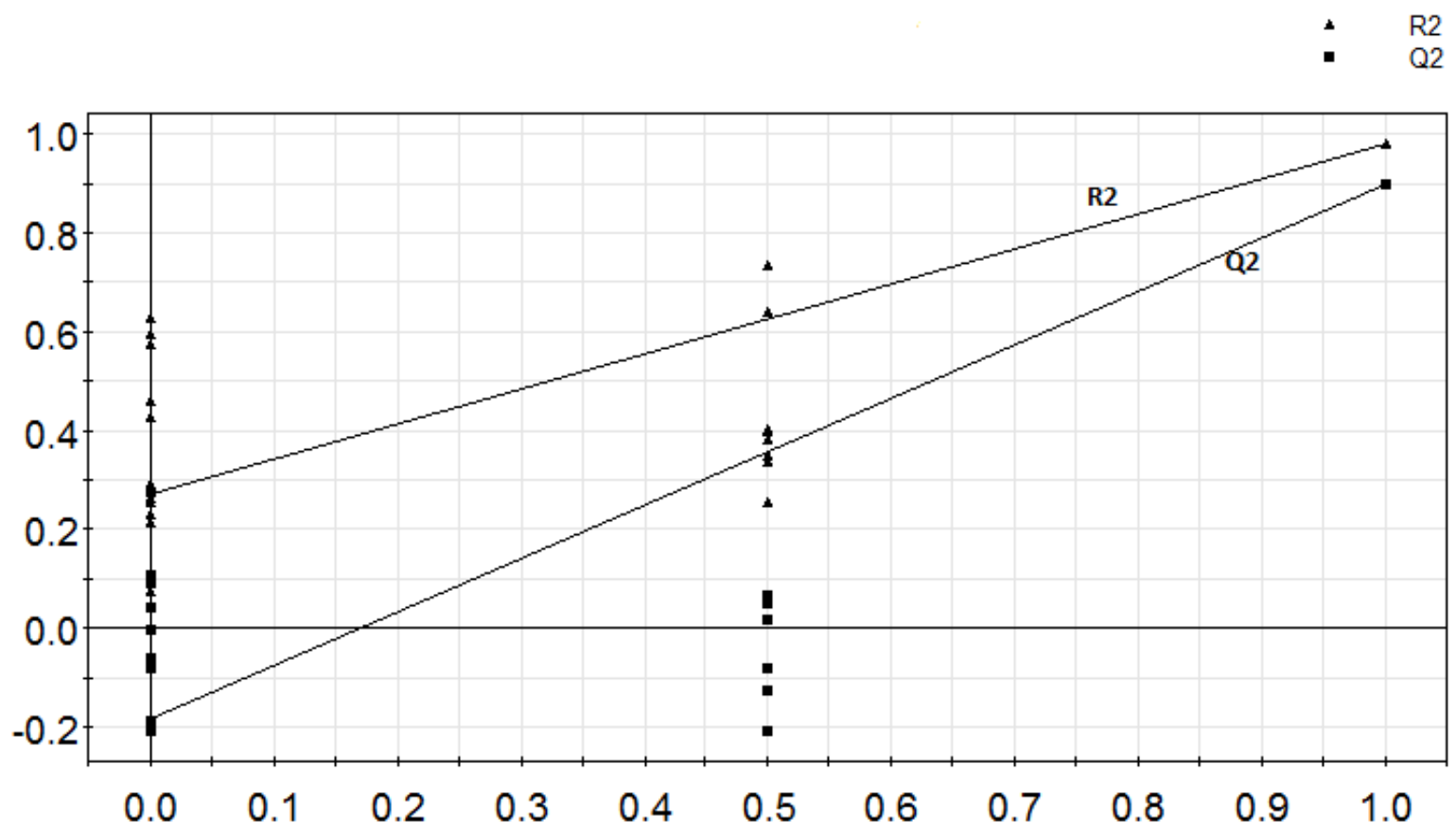

Pineapple breads (Cpb, Fpb and Ppb) were separated according to their processing methods (Figure 1). While conventionally baked pineapple bread $(\mathrm{Cpb})$ was situated in the area of positive components 1 and 2, the fully frozen baked pineapple bread (Fpb) was within the area of positive component 1 and negative component 2 respectively. However, partially baked pineapple bread $(\mathrm{Ppb})$ was situated in the area of negative component 1 and positive component 2 respectively. The inter-relationship between the pineapple breads ( $\mathrm{Cpb}, \mathrm{Fpb}$ and $\mathrm{Ppb}$ ) and the volatile- and non-volatile compounds were examined by the PLS-regression coefficients of scaled and centred variables (Figure $3 \mathrm{~A}-\mathrm{C}$ ). Meanwhile, the $\mathrm{Cpb}$ showed significant $(p<0.05)$ positive correlation with hexanal and 4-hydroxy-2,5-dimethyl-3(2H)furanone, it however, revealed strong negative correlations with benzoic acid, benzaldehyde, and ethyl propionate (Figure 3A). On the other hand, Fpb, revealed strong positive correlations with lactic acid, benzoic acid, benzaldehyde and ethyl propionate (Figure 3B). Moreover, the Ppb showed positive correlations with most of the volatile- and non-volatile compounds respectively (Figure 3C). It however, showed negative correlations with only two compounds namely; benzaldehyde and ethyl propionate. As can be seen, while the alcohols (ethanol, 2/3-methyl-1-butanol and 2-phenylethanol) and the acids showed high positive correlations in the partially baked pineapple bread (Ppb), they however, revealed negative correlations in both conventional and fully frozen baked pineapple breads (Figure 3A-C). Previous studies on sourdoughs [26-28] have shown that the presences of acids in sourdoughs are positively valued, as they strengthen the flavour.

As the conventional pineapple bread $(\mathrm{Cpb})$ and the fully frozen pineapple bread (Fpb) were based on the same recipe and fermentation regime, the differences identified in their volatile compounds may be linked to the freezing and thawing stages that distinguished them. 
Figure 3. The regression coefficients of scaled and centered variables for the response components. A: Cpb; B: Fpb and C: Ppb.
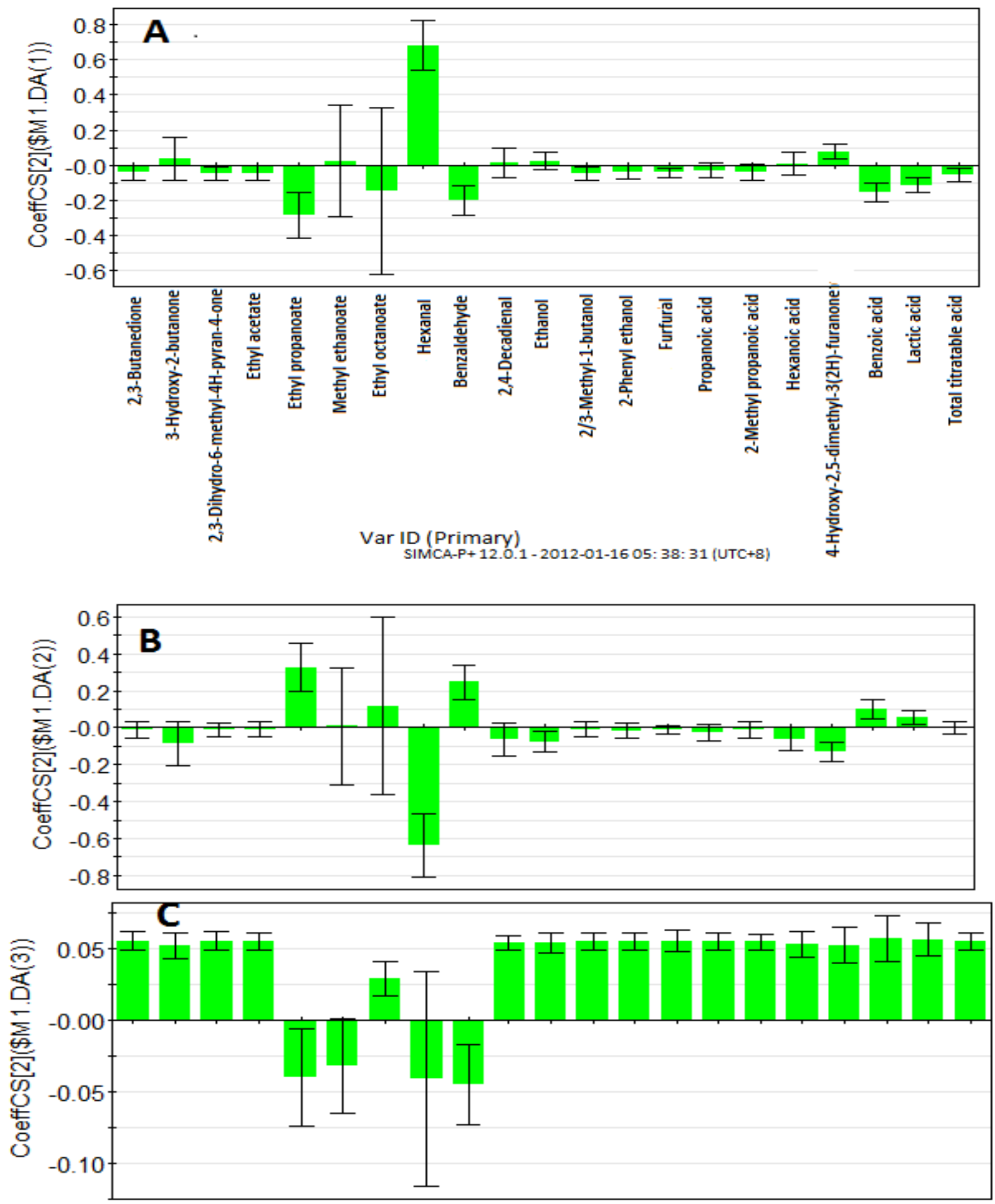

\section{Experimental}

\subsection{Materials}

All experiments were carried out with flour purchased from a local market in Malaysia. Its composition was: $12 \%$ protein, $13.5 \%$ moisture basis and $77 \%$ starch (determined by a Megazyme 
starch kit, Megazyme Int., Wicklow, Ireland), of which 5\% was damaged starch (determined by a Megazyme damaged starch kit). Fresh pineapple fruits (Ananas comosus L) of Josephine cultivar with similar characteristics of ripening (skin colour, flat eyes and Brix) were used.

\subsection{Chemicals}

The following odourants: 97\% 2-methyl-1-butanol, 96\% 3-methyl-1-butanol, 98\% 2-phenyl ethanol, 98\% 1-butanol, 96\% acetic acid, 98\% propanoic acid, 97\% hexanoic acid, 96\% 4-hydroxybutanoic acid, 89\% benzoic acid, 97\% hexanal, 98\% benzaldehyde, 98\% (E,E)-2,4-decadienal, 97\% furfural, 98\% furfuryl alcohol, 98\% ethyl acetate, 98\% ethyl propanoate, 97\% methyl ethanoate, 97\% ethyl octanoate, 98\% 2-methylpropanoic acid, 96\%; were obtained from (Aldrich, Steinheim, Germany); 99\% 2,3-butanedione, 98\% 4-hydroxy-2,5-dimethyl-3(2H)-furanone, 98\% 3-hydroxy-2butanone were purchased from Fluka (Neu-Ulm, Germany). Stock standard solutions of $10^{3}$ or $10^{4} \mathrm{mg} \mathrm{L}^{-1}$ of each component were prepared by dissolving the pure standard in $40 \%(\mathrm{v} / \mathrm{v})$ ethanol. The samples were stored at $4{ }^{\circ} \mathrm{C}$. Working standard solutions were prepared daily by mixing an aliquot of each individual solution and diluting with ultra pure water (Millipore Co., Bedford, MA, USA) to obtain a desired concentration.

\subsection{Sample Preparation}

Preparation of Pineapple Juice Concentrates

Fresh pineapple fruits were washed in cold tap water and drained. They were manually cut up and the juice extracted in a Panasonic juice extractor (MJ-7 juice extractor, Panasonic, Bracknell, U.K). The juice $(1,000 \mathrm{~mL})$ obtained was filtered, dispensed in a beaker and replaced on the centre of a programmable domestic Panasonic microwave oven (Model NN 573-MF) with maximum output of $700 \mathrm{~W}$ at 2,450 MHz The oven has adjustable power (wattage) and time controllers, and was fitted with a turntable. Heating was carried out at $350 \mathrm{~W}$ for $23 \mathrm{~min}$.

\subsection{Bread Preparation}

The recipes and the production processes of the pineapple breads are as shown in Figure 4 [15]. For the preparation of the pineapple breads, three different methods (conventional, fully baked and frozen and partially baked) were employed. The dough was mixed in a KN-200 mixer (Taisho, Denki Co., Ltd., Shiga, Japan) for $7 \mathrm{~min}$ at $380 \mathrm{rpm}$. The dough was flattened with a roller to obtain a round, symmetrical and homogenous thick sheet. It was then divided into 20 samples of $150 \mathrm{~g}$ pieces and allowed to rest for $20 \mathrm{~min}$ at room temperature. The dough pieces were divided into two batches (i.e., 10 samples of $150 \mathrm{~g}$ pieces). 
Figure 4. Flow sheet on the fermentation steps and the production procedure for the different pineapple breads $(\mathrm{CPb}, \mathrm{FPb}$ and $\mathrm{PPb})$.

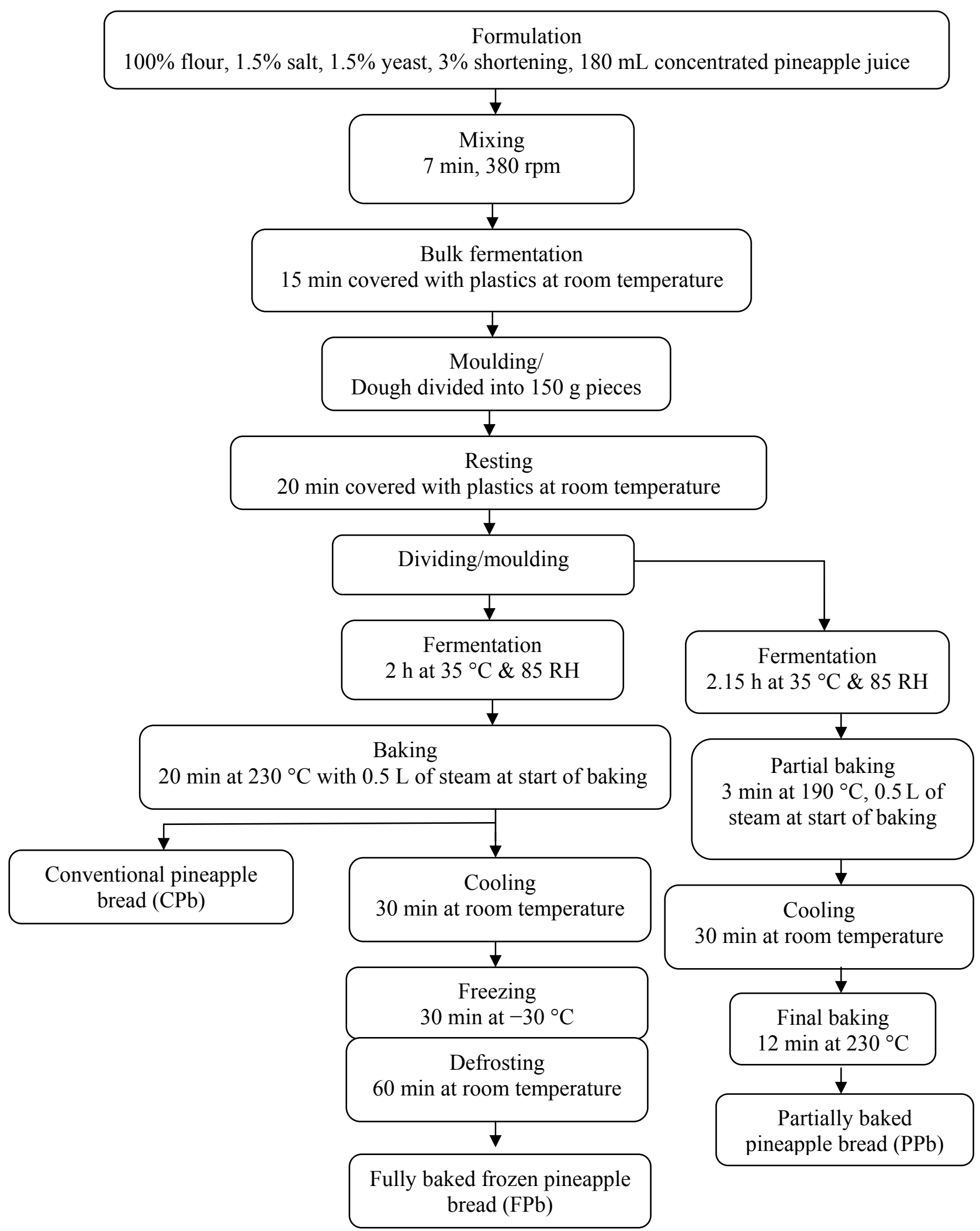

One batch was fermented for $2 \mathrm{~h}$ at $35^{\circ} \mathrm{C}$ and 85 relative humidity (RH) while the second batch was fermented for $2.15 \mathrm{~h}$ at $35^{\circ} \mathrm{C}$ and $85 \mathrm{RH}$. After fermentation, the first batch was baked at $230{ }^{\circ} \mathrm{C}$ 
for 20 min with an initial $0.5 \mathrm{~L}$ steam at the start of baking in a ventilated oven. Baked samples were further divided into two groups. A group is referred to as the conventional pineapple bread (Cpb) while the other group was frozen at $-30{ }^{\circ} \mathrm{C}$ for $30 \mathrm{~min}$ and latter defrosted at room temperature for $60 \mathrm{~min}$. This group is referred to as the fully baked frozen pineapple bread (Fpb).

The second fermented batch was partially baked at $190{ }^{\circ} \mathrm{C}$ for $3 \mathrm{~min}$ with $0.5 \mathrm{~L}$ steam at the start of baking similarly to the first batch. The baked bread sample was cooled for $30 \mathrm{~min}$ at room temperature and final baking was carried out in a static oven at $230{ }^{\circ} \mathrm{C}$ for $12 \mathrm{~min}$. This sample is referred to as partially baked pineapple bread (Ppb).

\subsection{Sensory}

The sensory acceptability of the pineapple breads ( $\mathrm{Cpb}, \mathrm{Fpb}$ and $\mathrm{Ppb}$ ) were determined using 24 University Putra Malaysia students whose ages ranged from 19 to 30 years. The students were made up of 12 females and 12 males, respectively. The samples were coded with a three-digit randomised number. The panellists were provided with water as mouth rinse. Each partitioned booth in the taste panel section was lighted with natural white fluorescent light. Panellist scored the breads according to a preference protocol including a scale from 0 (unacceptable) to 10 (excellent) [29]. Odour intensity was monitored using an odour intensity scale, which provides a verbal description of an odour sensation to which a numerical value is assigned (i.e., $0=$ no odour; 1 = very weak; 2 = weak; $3=$ distinct; $4=$ strong; $5=$ very strong and $6=$ intolerable) [7].

\subsection{Acidity Analysis}

Total titratable acidity (TTA) was measured using the method described by Martinez-Anaya and others [30] and lactic acid was determined using the method described by Quilez and other [31].

\subsection{Headspace Solid-Phase Microextraction (HS-SPME)}

A cross sectional cut (10 $\mathrm{g}$ of each bread samples) obtained from the central part was mixed together with $\mathrm{NaCl}\left(10 \mathrm{~mL}, 1 \mathrm{~g} \cdot \mathrm{mL}^{-1}\right)$ and shaken for $30 \mathrm{~s}$. Five grams of this mixture was placed in a $125 \mathrm{~mL}$ flask with a magnetic stirring bar and $5 \mu \mathrm{L}$ of internal standard and closed with cap. The flask was incubated for $60 \mathrm{~min}$ in a heated tray oven at $40{ }^{\circ} \mathrm{C}$. An SPME fibre with two different coatings $\left(75 \mu \mathrm{m}\right.$ carboxen $^{\mathrm{TM}} /$ polydimethylsiloxane; CAR/PDMS stablFlex ${ }^{\mathrm{TM}}$ ) (Supelco Co., Bellefonte, PA, USA) was inserted in the headspace of the vial for $10 \mathrm{~min}$ to collect the volatiles. The type of fibre used can often affect the selectivity of the extraction and by using a mixed type; good selectivity is obtained for non-polar analyte as well as for polar analyte. This type of fibre was used successfully in the past for the characterisation of the aroma compounds of partially baked bread [11]. After each extraction, the fibre was inserted into the GC injector port using a $0.75 \mathrm{~mm}$ i.d liner (in order to improve the GC resolution). Desorption time and temperature were $5 \mathrm{~min}$ and $250{ }^{\circ} \mathrm{C}$ respectively. All experiments and sample measurements were carried out in triplicate and the average values were recorded. 


\subsection{GC-MS Analysis}

The identification and quantification of volatile compounds was carried out with a Shimadzu (Kyoto, Japan) QP-5050A GC-MS instrument equipped with a GC-17A Ver. 3 gas chromatograph with a flame ionization detector (FID). The column was a DB-5 column $(30 \mathrm{~m} \times 0.32 \mathrm{~mm}$ i.d., film thickness $0.25 \mu \mathrm{m}$ J \& W Scientific, Folsom, CA, USA). Helium was used as carrier gas at a flow rate of $1.5 \mathrm{~mL} \mathrm{~min}{ }^{-1}$, injection temperature, $250{ }^{\circ} \mathrm{C}$; detector temperature, $280{ }^{\circ} \mathrm{C}$; temperature program commenced at $50{ }^{\circ} \mathrm{C}$ and held for $3 \mathrm{~min}$, then raised to $250{ }^{\circ} \mathrm{C}$ at a rate of $15^{\circ} \mathrm{C} \mathrm{min}{ }^{-1}$, held for $10 \mathrm{~min}$ and then increased to $280{ }^{\circ} \mathrm{C}$ at a rate of $10^{\circ} \mathrm{C} \mathrm{min}{ }^{-1}$, with a final hold time of $5 \mathrm{~min}$. The effluent from the capillary column was split into 2:1 (by vol.) onto two uncoated but deactivated fused silica capillaries $(50 \mathrm{~cm} \times 0.32 \mathrm{~mm})$ leading to a FID and a sniffing port.

The mass spectrometer was operated in electron impact mode with the following conditions. The source temperature was $250{ }^{\circ} \mathrm{C}$; the quadruple temperature selected was $280{ }^{\circ} \mathrm{C}$ and the relative electron multiplier voltage (EM) applied was $400 \mathrm{~V}$ with a resulting voltage of $1,553 \mathrm{~V}$. In order to improve the detection limits, the selected ion monitoring (SIM) mode was used. Compounds identification was based on comparison of linear retention indices (RI), mass spectra (comparison with standard MS spectra databases: Wiley 6), and injection of standards. The quantification was performed using 1-butanol as the added standard. The concentrations of volatile compounds were expressed in microgram equivalents of 1-butanol per gram of bread.

\subsection{GC-Olfactrometry Analysis}

Each bread sample (dry weight) (400 g) was mixed with water $(1,800 \mathrm{~mL})$ in a 4-litre distilling flask. The distilling flask was heated in a water bath at $40{ }^{\circ} \mathrm{C}$ and the volatile compounds were steam distilled under vacuum (30 mbar) for $5 \mathrm{~h}$. The distillate was extracted with dichloromethane, dried with sodium sulphate and concentrated to $50 \mu \mathrm{L}[26]$.

GC-olfactometry analysis was performed on a Thermo Scientific GC instrument (Thermo Fisher Scientific, Rivoltana, Italy) equipped with a split-splitless injector, a FID and an ODP 3 Olfactory Detector Port (Gerstel, Mulheim, Germany). At the column outlet, the eluate was split 1:1 to simultaneously detect volatile compounds by FID and sniffing. Samples $(4 \mu \mathrm{L})$ were separated on a $60 \mathrm{~m} \times 0.32 \mathrm{~mm}$ i.d., $0.25 \mu \mathrm{m}$ film thickness DB-5 column (J \& W Scientific) according to the same temperature programmed as reported for the GC-MS analysis. Helium was used as a carrier gas at the flow rate of $1.5 \mathrm{~mL} \mathrm{~min}{ }^{-1}$. Injector and FID temperature was $250{ }^{\circ} \mathrm{C}$; hydrogen, air and nitrogen (make up) flow rates were 30,450 and $30 \mathrm{~mL} \mathrm{~min}^{-1}$ respectively. The sniffing was performed by three trained panellists, who presented satisfactory sensitivity and reproducibility and agreement with one another. For each GC-O analysis, sniffing was divided into three sessions of 20 min and panellists were asked to characterise the detectable aroma with a freely chosen descriptor.

\subsection{Aroma Extracts Dilution Analysis (AEDA)}

The FD factors of the odour-active compounds were determined by AEDA [32]. Each bread sample $(200 \mathrm{~g})$ was immediately frozen with liquid nitrogen and later homogenized with anhydrous sodium sulphate (200 g) in a commercial blender (Moulinette, Numberg, Germany). The powder was extracted 
with dichloromethane $(1 \mathrm{~L})$ for $8 \mathrm{~h}$ at $40{ }^{\circ} \mathrm{C}$ using a Soxhlet extractor. The extract was concentrated to $\sim 100 \mathrm{~mL}$ by distilling off the solvent. The distillate was extracted with an aqueous sodium carbonate $(0.5 \mathrm{~mol} / \mathrm{L}, 3 \times 50 \mathrm{~mL})$ to remove acidic volatiles. The aqueous solution was washed with dichloromethane $(50 \mathrm{~mL})$, and the organic phase were combined, dried over anhydrous sodium sulphate, filtered, and concentrated to $\sim 0.1 \mathrm{~mL}$. The following series: the neutral-basic and acidic fractions were step wisely diluted with dichloromethane $(1+1, \mathrm{v} / \mathrm{v})$, and each dilution was analyzed by gas chromatography/olfactometry to give the flavour dilution (FD) factors of odour-active compounds.

\subsection{Statistical Analysis}

Raw data obtained from each sensory session were averaged across panellists, and the results were studied by one-way analysis of variance (ANOVA). Duncan's multiple range tests were used to determine significance among results. Partial least square discriminant analysis (PLS-DA) and PLS-regression coefficient were chosen as an exploratory technique to describe and summarise data by grouping variables that are correlated. The multivariate statistical analyses were performed with the SIMCA-P software (v. 12.0, Umetric, Umeå, Sweden) [33] PLS regression is specifically designed to determine relationships which exist between blocks of dependent (Y, bread types) and independent (X, volatiles) variables by seeking underlying factors common to both sets of variables [24].

\section{Conclusions}

The sensory profiles for the different pineapple breads ( $\mathrm{Cpb}, \mathrm{Fpb}$ and $\mathrm{Ppb}$ ) were found to be affected by processing parameters such as fermentation time, freezing and baking protocols. While the partially baked pineapple bread $(\mathrm{Ppb})$ produced higher intensity of dough and sourdough like flavour with slight fruity notes, the other two pineapple breads ( $\mathrm{Cpb}$ and $\mathrm{Fpb}$ ) produced much lower flavour nuances. The AEDA results revealed the 19 most odour-active compounds with flavour dilution (FD) factors in the range of $32-128$ as the key odourants of the pineapple breads. Further analysis of the similarities and differences between the pineapple breads in terms of the key odourants were carried out by the application of PLS-DA and PLS-regression coefficients. Results showed that Ppb exhibited strong positive correlations with most of the volatile- and non-volatile compounds, while the $\mathrm{Cpb}$ showed significant positive correlations with hexanal and 4-hydroxy-2,5-dimethyl-3(2H)-furanone, and the Fpb had strong positive correlations with lactic acid, benzoic acid, benzaldehyde and ethyl propanoate. These different pineapple breads are important products in terms of innovation and they represent processes that reduce cereal waste.

\section{Acknowledgments}

The authors are grateful to the University Putra Malaysia for the Research grant (RUGs, No. 916700).

\section{References}

1. Pozo-Bayon, M.A.; Guichard, E.; Cayot, N. Flavour control in baked cereal products. Food Rev. Int. 2006, 22, 335-379.

2. Cayot, N. Sensory quality of traditional foods. Food Chem. 2007, 101, 154-162. 
3. Ruiz, J.A.; Quilez, J.; Mestres, M.; Guasch, J. Solid-phase micro extraction method for headspace analysis of volatile compounds in bread crunch. Cereal Chem. 2003, 80, 255-259.

4. Grosch, W.; Schieberle, P. Flavour of cereal products-a review. Cereal Chem. 1997, 74, 91-97.

5. Schieberle, P.; Grosch, W. Potent odorants of the wheat bread crumb. Differences to the crust and effect of longer dough fermentation. Zeits fur Lebensm Unter und Forsch 1991, 192, 130-135.

6. Chang, C.Y.; Seitz, L.M.; Chambers, E. Volatile flavour components of breads made from hard red winter wheat and hard white winter bread. Cereal Chem. 1995, 72, 237-242.

7. Jiang, J.; Coffey, P.; Toohey, B. Improvement of odour intensity measurement using dynamic Olfactometry. J. Air Waste Manag. Assoc. 1995, 56, 675-683.

8. Rychlik, M.; Grosch, W. Identification and quantification of potent odorants formed by toasting of wheat bread. LWT-Food Sci. Technol. 1996, 29, 515-525.

9. Frasse, P.; Lambert, S.; Richard-Molard, D.; Chiron, H. The influence of fermentation on volatile compounds in French bread dough. LWT-Food Sci. Technol. 1993, 25, 66-70.

10. Schieberle, P. Intense aroma compounds-useful tools to monitor the influence of processing and storage on bread aroma. Adv. Food Sci. 1996, 18, 237-244.

11. Poinot, P.; Gnua-Priol, J.; Arvisenet, G.; Rannou, C.; Semenou, M.; Lebail, A.; Prost, C. Optimizations of HS-SPME to study representativeness of partially baked bread odorant extracts. Food Res Int. 2007, 40, 1170-1184.

12. Ho, C.W.; Wan Aida, W.M.; Maskat, M.Y.; Osman, H. Optimization of headspace Solid- phase micro extraction (HS-SPME) for gas chromatography-mass spectrometry (GC-MS) analysis of aroma compound in Palm sugar (Arenga pinnata). J. Food Comp. Anal. 2006, 19, 822-830.

13. Lasekan, O. Headspace solid-phase micro extraction gas chromatography-mass spectrometry (HS-SPME-GC-MS) determination of volatile compounds in roasted plantains (French sombre and Dwarf kalapua). LWT-Food Sci. Technol. 2012, 46, 536-541.

14. Skrbic, B.; Filipcer, B. Nutritional and sensory evaluation of wheat breads supplemented with oleic-rich sunflower seed. Food Chem. 2008, 108, 119-129.

15. Lasekan, O.; Chima, C.; Ossai, B.; Mohd Adzahan, N. Effect of different pineapple juice (Ananas comosus L) preparations on the microstructure, staling and textural properties of wheat bread. J. Food Proc. Eng. 2011, 34, 1449-1463.

16. Kermasha, S.; Barthakur, N.N.; Alli, I.; Mohan, N.K. Changes in Chemical composition of the Kew cultivars of pineapple fruit during development. J. Sci. Food Agric. 1987, 39, 317-324.

17. Armbruster, D.A.; Tillman, M.D.; Hubbs, L.M. Limit of detection (LOD), limit of quantization (LOQ): Comparison of the empirical and the statistical methods exemplified with GC-MS assays of abused drugs. Clin. Chem. 1994, 40, 1233-1238.

18. Adams, R.P. Identification of Essential Oil Components by Gas Chromatography/Mass Spectrometry, 2nd ed.; Allured Publishing Corporation: Carol Stream, IL, USA, 2007.

19. Elss, S.; Preston, C.; Hertzig, C.; Heckel, F.; Richling, E.; Schreier, P. Aroma profiles of pineapple fruit and pineapple products. J. Food Sci. Technol. 2005, 38, 263-274.

20. Jensen, S.; Oestdal, H.; Skibsted, L.H.; Larsen, E.; Thybo, A.K. Chemical changes in wheat pan bread during storage and how it affects the sensory perception of aroma, flavor, and taste. J. Cereal Sci. 2011, 53, 259-268. 
21. Schieberle, P.; Grosch, W. Potent odorants of rye bread crust-differences from the crumb and from wheat bread crust. Zeit fur Lebensm und Forsch 1994, 198, 292-296.

22. Silva, U.F.D.; Borba, E.L.; Semir, J.; Marsaioli, A.J. A simple solid injection device for the analysis of Bulbophyllum volatiles. Phytochemistry 1999, 50, 31-34.

23. Tokitomo, Y.; Steinhaus, M.; Buettner, A.; Schieberle, P. Odor-active constituents in fresh pineapple (Ananas comosus) by quantitative and sensory evaluation. Biosci. Biotechnol. Biochem. 2005, 69, 1323-1330.

24. Zehentbauer, G.; Grosch, W. Crust aroma of baguettes, 11. Dependence of the concentration of key odorants on yeast level and dough processing. J. Cereal Sci. 1998, 28, 93-96.

25. Lonner, C.; Preve-Akesson, K. Effects of lactic acid bacteria on the properties of sour dough bread. Food Microbiol. 1989, 6, 19-35.

26. Lasekan, O.; Buettner, A.; Christlbauer, M. Investigation of Important odorants of palm wine (Elaeis guineensis). Food Chem. 2007, 105, 15-23.

27. Plessas, S.; Fisher, A.; Koureta, K.; Psarianos, C.; Nigam, P.; Koutina, A.A. Application of Kluyveromyces marxianus, Lactobacillus derbrueckii and L. helveticus for sourdough bread making. Food Chem. 2008, 106, 985-990.

28. Hansen, A.; Lund, B.; Lewis, M.J. Flavour production and acidification of sour dough in relation to starter culture and fermentation temperature. LWT-Food Sci. Technol. 1989, 22, 145-149.

29. Martens, H.; Naes, T. Multivariate Calibration; Wiley Ltd.: New York, NY, USA, 1989; pp. 419-422.

30. Martinez-Anaya, M.A.; Pitarch, B.; Bayarri, P.; Benedito, A.; de Barber, C. Microfloral of the sourdoughs of wheat bread. X. Interactions between yeasts and lactic acid bacteria in wheat doughs and their effects on bread quality. Cereal Chem. 1990, 67, 85-91.

31. Quilez, J.; Ruiz, J.A.; Romero, M.P. Relationship between sensory flavour evaluation and volatile and non-volatile compounds in commercial wheat type baguette. J. Food Sci. 2006, 71, 423-427.

32. Czerny, M.; Schieberle, P. Important aroma compounds in freshly ground whole meal and white wheat flour-identification and quantitative changes during sourdough fermentation. J. Agric. Food Chem. 2002, 50, 6835-6840.

33. Eriksson, L.; Johansssen, E.; Kettaneh-Wold, N.; Wold, S. Multi and megavariate Data Analysis; Umetrics AB: Umea, Sweden, 2006.

Sample Availability: Not available.

(C) 2012 by the authors; licensee MDPI, Basel, Switzerland. This article is an open access article distributed under the terms and conditions of the Creative Commons Attribution license (http://creativecommons.org/licenses/by/3.0/). 